\title{
Chapter 18 \\ Sustainable Management of Urban Green Environments: Challenges and Opportunities
}

\author{
Samuel Kiboi, Kazue Fujiwara, and Patrick Mutiso
}

\begin{abstract}
Urban green areas not only provide aesthetic qualities but also provide important ecosystem services in ever-shrinking habitats, and therefore need sustainable management practices. The western and northwestern parts of Nairobi are within an upland dry forest that stretched from Karura to Ngong forests with a characteristic vegetation composition. Much of that vegetation has been replaced by exotic species and, over time, the original indigenous tree species composition may be lost. No previous studies have profiled the local vegetation structure in Kenya and then used this knowledge to restore the urban green environment. We carried out studies in Karura and Ngong forests and used 16 carefully selected species to recreate a natural forest using the 'Miyawaki method' at the College of Biological and Physical Sciences of the University of Nairobi. In just 16 months the species have established extremely well, with the best performing species (Ehretia cymosa) growing to more than $210 \mathrm{~cm}$ from just about $43 \mathrm{~cm}$. We expect to recreate a quasinatural forest and use such studies and methods to restore urban green environments in Kenya.
\end{abstract}

Keywords Natural green environment restoration - Upland dry forests • Urban forest ecosystem services $\bullet$ Urban vegetation • Vegetation structure of Nairobi

\footnotetext{
S. Kiboi $(\bowtie) \cdot$ P. Mutiso

School of Biological Sciences, University of Nairobi, Nairobi, Kenya

e-mail: samuel.kiboi@uonbi.ac.ke; mutiso_chalo@uonbi.ac.ke

K. Fujiwara

Graduate School in Nanobioscience, Yokohama City University, Yokohama, Japan

e-mail: kazue@ynu.ac.jp
} 


\subsection{Introduction}

Urban green environments in developing countries especially are under constant pressures resulting from rapid urbanization, which can be sometimes unplanned. The greatest challenge today is to manage the environment in a sustainable way whilst offering pleasant surroundings for the urban dweller, and at the same time maintaining some natural areas. Nairobi, for example, has been ranked among the top ten cities in the world that have the biggest declines in liveability over 5 years with a score of $-2.9 \%$ according to the latest Global Liveability Survey of 140 cities worldwide (Economist Intelligence Unit 2013). The unit measured cost of living, health care, pollution, education, infrastructure, and green spaces to obtain the scores. In general, green environments, and specifically trees, offer an array of benefits that can be categorized broadly into: ecological benefits, architectural functions, climate moderation, and monetary benefits, as well as recreational and social values (TEEB 2011; Bolund and Hunhammar 1999).

\subsection{Challenges in Achieving Sustainable Green Urban Environments}

The challenges to sustainable green environments in urban areas are many and require a proactive approach and the cooperation of all citizenry. Apart from an effective regulatory system, an informed citizenry will keep the environment in better condition than those who have to be policed to adhere to standards. Some of the problems facing urban areas in Kenya are severe and common to many cities in the developing world, although they may vary in magnitude. Management of urban environments in the developed world is more effective, and hence the environments are cleaner and greener but may have experienced pollution challenges in the past, e.g., Yokohama in Japan had major pollution problems in the 1960s. Some of the major environmental challenges facing urban environments in Kenya are:

\subsubsection{Waste Management}

Waste management is the biggest environmental problem in most urban areas and can lead to environmental pollution in many ways and affect drainage systems (Figs. 18.1, 18.2, and 18.3). The amount of solid waste generated per individual, homestead, or industry is usually high and requires a very comprehensive collection and disposal mechanism, ideally with facilities for sorting at source. In such cases organic waste is converted to manure or used to produce energy while most other types of waste are recycled. When it comes to liquid waste and effluents from industries, proper mechanisms are required to treat the waste to levels where no harm can result from discharging back to the environment. 


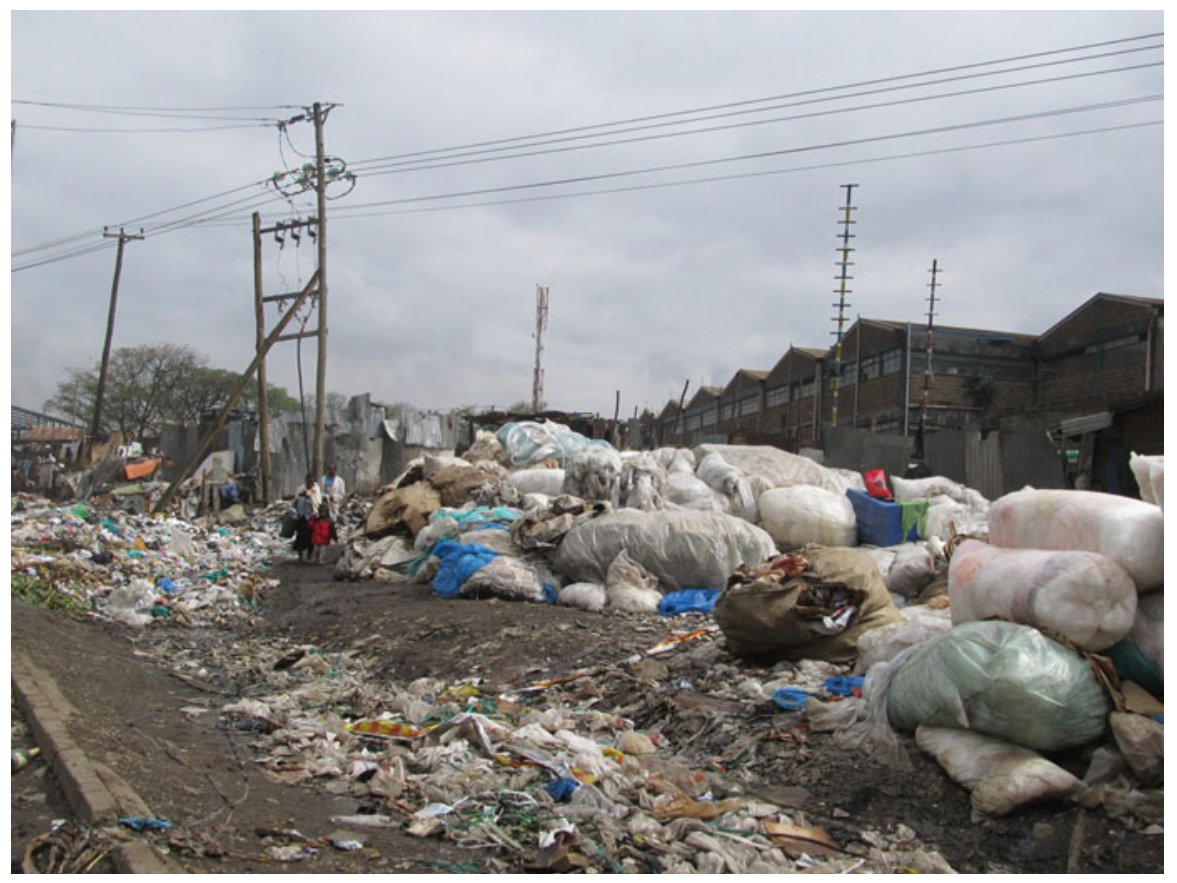

Fig. 18.1 An unregulated roadside garbage dump site in Nairobi where informal sorting of polythene is also undertaken

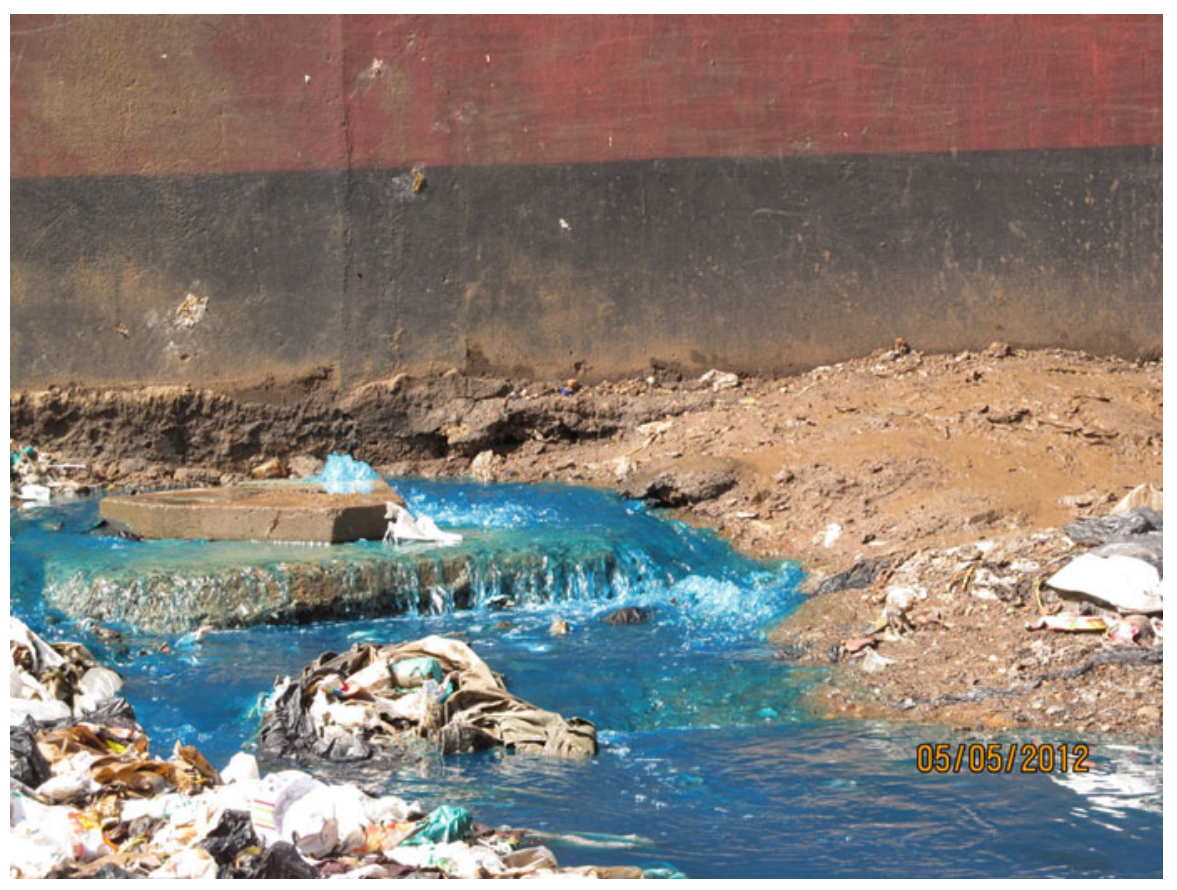

Fig. 18.2 Industrial effluent discharge from a blocked sewer line showing waste treatment may be inadequate 


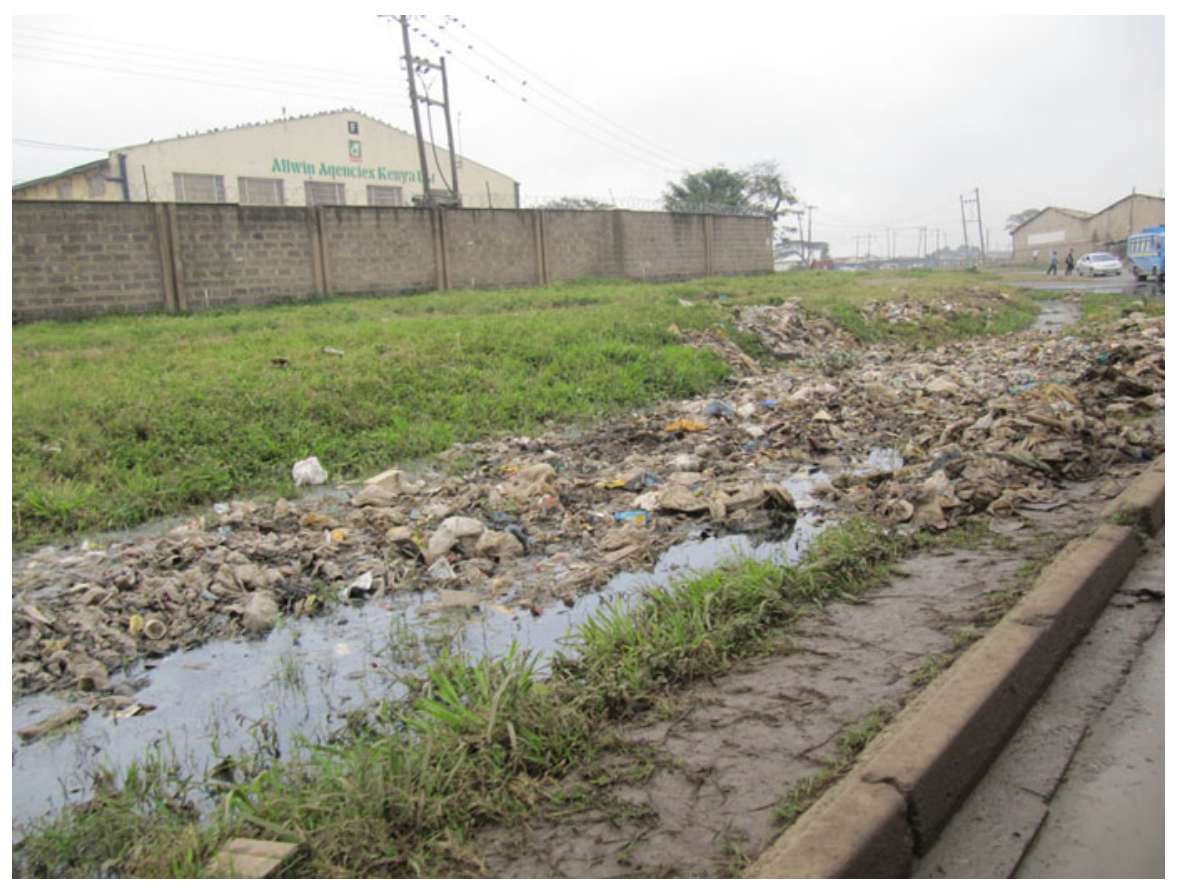

Fig. 18.3 Solid waste blocking drainage systems in Nairobi, Kenya

\subsubsection{Air Pollution}

Air pollution comes from different sources in urban environments. The first major source is combustion of fossil fuels from vehicles and industries (Fig. 18.4). As the middle class continues to expand in developing countries, so do the number of vehicles on the roads. The maintenance of vehicles is usually a major contributor to how efficient their combustion process is and those that are badly maintained will emit exhaust gases that are not well combusted. This, combined with bad fuel quality, exacerbates the problem. Bad fuel quality may be due to use of outdated crude oil refining technology or due to illegal adulteration of fuel by mixing different types, e.g., diesel with kerosene.

Other sources of air pollution include burning of waste and, perhaps worst of all, rubber (e.g., burning old tires to remove the steel ply inside) and plastic waste, especially in unmanaged dumpsites. Rubber and plastics release substantial amounts of toxic gases into the air which not only contributes to global warming but also to health problems among those inhaling the air. Open tire fire emissions include pollutants, such as particulates, carbon monoxide $(\mathrm{CO})$, sulfur oxides $\left(\mathrm{SO}_{2}\right)$, oxides of nitrogen $\left(\mathrm{NO}_{\mathrm{x}}\right)$, and volatile organic compounds (VOCs). They also include hazardous air pollutants (HAPs), such as polynuclear aromatic hydrocarbons (PAHs), dioxins, furans, hydrogen chloride, benzene, polychlorinated biphenyls (PCBs), and metals such as arsenic, cadmium, nickel, zinc, mercury, chromium, and vanadium (Lemieuxa et al. 2004). 


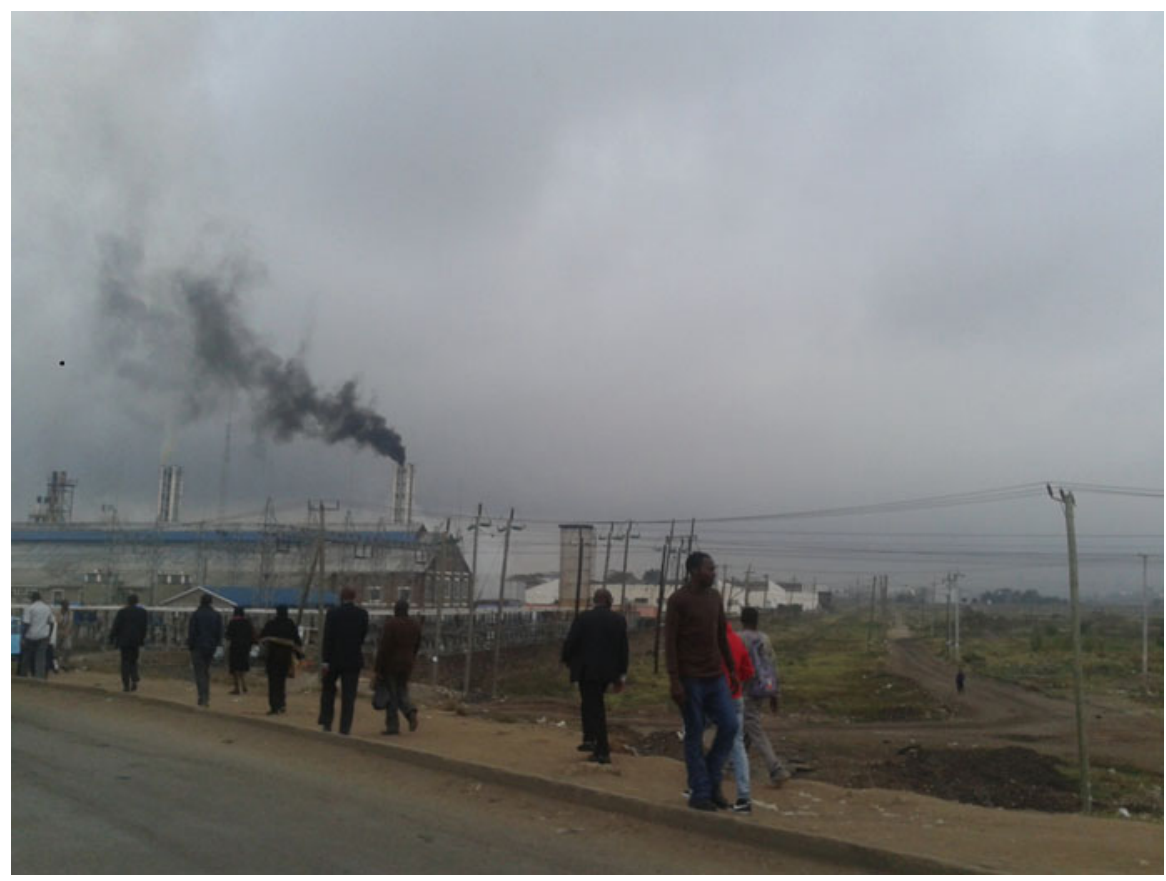

Fig. 18.4 Emission of gases from fossil fuels contribute to the amount and concentration of greenhouse gases in cities such as Nairobi

Lack of grass cover or properly paved roads and walkways leaves the soil exposed and constant traction by vehicles and human traffic results in dusty conditions that lead to respiratory diseases, as well as dusty buildings and installations. Urban dust is more likely to carry harmful substances including microbes, because often drainage systems block due to runoff soil and organic waste flooding the roads, and the micro-organisms can then be spread via dust. Therefore, if well-managed green areas and paved surfaces exist, these problems would be minimized.

\subsubsection{Infrastructure}

Infrastructure development is a key measure of urban growth. All developments should ideally be well planned with the necessary regulatory approvals including minimizing environmental impacts by undergoing an impact evaluation. Measures to mitigate environmental impact should be put in place during project implementation and maintained after commissioning. In Kenya for example, the National Environmental Management Authority (NEMA) or Environmental and Social Impact Assessment (ESIA) - (depending on scope) has to approve all projects after an Environmental Impact Assessment (EIA) has been conducted. Despite the regulations being followed, however, compliance challenges exist, especially in 


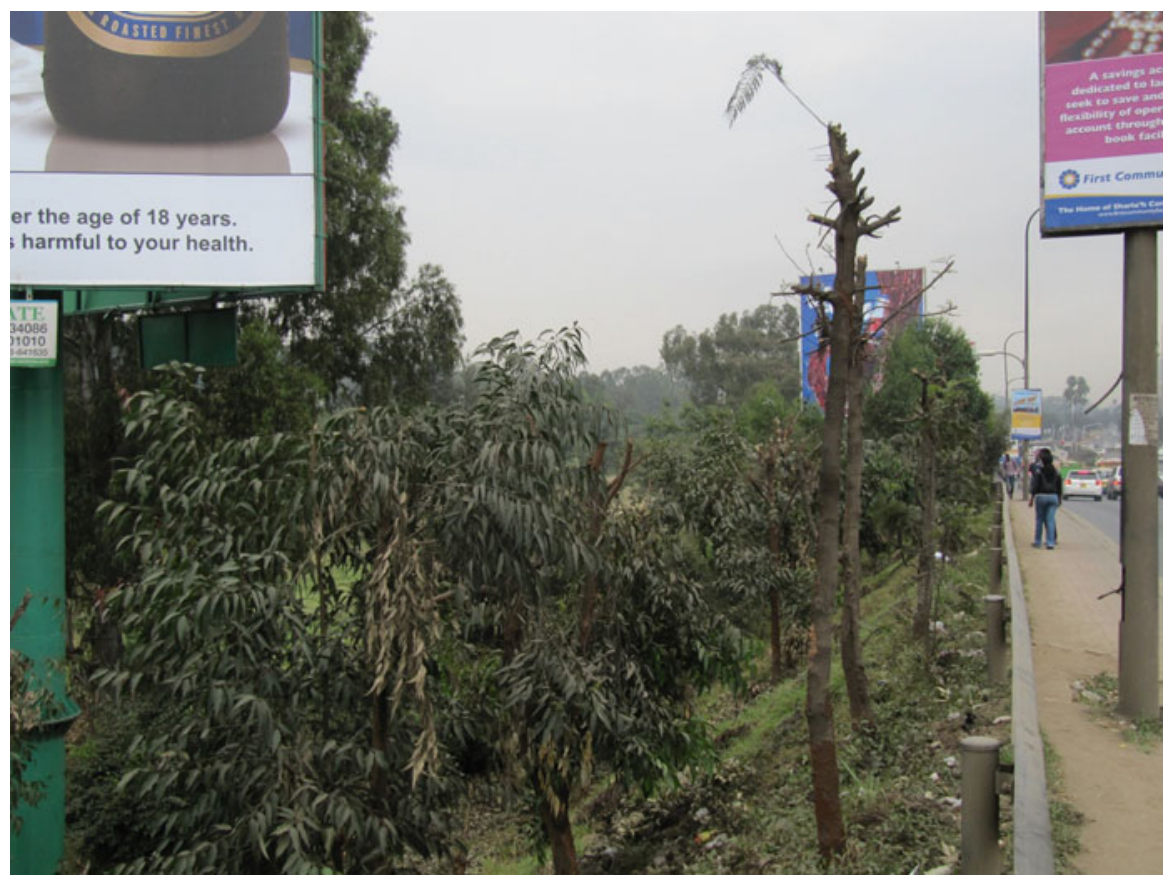

Fig. 18.5 Proper designation of clear zones along roadsides can help avoid such vegetation disturbance and better management for outdoor adversing space

ensuring that what is approved on paper is actually implemented during and after inception of the project. The capacity of such institutions may be limited such that each project is not monitored and assessed as it ideally should be.

An example of an urban environmental problem affecting green due to infrastructure development is the information technology industry. In the last 5 years or so, Kenya and the region as a whole have invested heavily in fiber optic connectivity with up to three international cable landings connecting Kenya and the rest of the world. Most if not all major towns now have a connection using the fiber optic network. Companies that have invested in the cable are now racing to connect as many buildings as possible and the negative effect of this is that there is no common cabling approach. This means that different companies dig up the same routes at different times and the result is repeated disturbance, while environmental restoration is not always to the previous standard or better.

Another example of challenges to green urban areas is the billboard advertising industry. While strategic positioning is important in brand visibility, urban greening programs could affect visibility over time as the trees mature. Observations around Nairobi show that this is countered by trimming trees, which is not ideal for coexistence between outdoor advertising industry and sound ecologically friendly urban environmental management (Fig. 18.5). This is a severe problem that needs to be addressed by the city management authorities and the advertising companies in conjunction with the NEMA. 


\subsection{Opportunities for Sustainable Green Urban Areas}

Trees offer opportunities to create multi-strata natural areas and absorb 25-30 times more $\mathrm{CO}_{2}$ than mono-strata grass surface areas, and therefore a scientifically guided restoration or reconstruction of green environments such as vegetation ecology or ecotechnology is desirable (Miyawaki 1998). Ecotechnology is a technological means of ecosystem management based on deep ecological understanding, to minimize costs of management measures and their harm to the environment (Straskraba 1993). Ecotechnology uses a vegetation ecology approach to build multi-strata greenery (e.g., canopy, understory, shrub, and herb layers) to fulfill the ecological potential of the area. Forests have different ecological functions and urban greening programs should not rely on the functions of green vegetation in general, but should address the suitability of different plants in light of the complexities of urban design and management. Such complexities may include: (1) open spaces such as parks, (2) areas along roads and walkways, (3) tracts of land along riverine areas and in wetlands, (4) mixed-use areas such as those around and within residential districts and other built-up areas, and (5) office and industrial zones.

Trees are the most memorable aspect of a roadside planting design. They have an appropriate scale for a road corridor, are clearly noticed when travelling and are the best means for ameliorating the hard built elements of the road corridor. Subject to their safe use, they should be the primary element of a landscape design. Trees should, however, be used selectively in a corridor. For example they should not obscure expansive views and they should be located carefully and deliberately, outside clear zones and away from utilities (Chang and Collins 2008)

Each urban district occurs in a distinct ecological area with unique naturally occurring plant species. These are species that have long adapted in these ecosystems and established their own niches in the communities that they occur in. In selecting tree species to plant in urban areas, this should be a key consideration to maintain natural environments. In many upcoming cities in the developing world, and in Kenya in particular, there seem to be no scientifically informed criteria for urban greening programs, and most of the time exotic species are planted. This may mainly be due to their visual appeal, availability, and growth under a wide breadth of ecological conditions (e.g., Grevilia robusta). Indigenous species are usually overlooked and this could be mainly because of insufficient understanding of their local suitability, optimum combinations, and interaction with other species, as well as impact on the infrastructure, among other considerations. Nonetheless, some other countries have made significant progress in urban green environments based on theories of vegetation ecology (Miyawaki 1998; Muller and Fujiwara 1998).

Some key benefits of green urban environments include carbon assimilation, disaster prevention and reduction, beautification and nutrition. 


\subsubsection{Carbon Assimilation}

Urban environments are major sources of carbon dioxide $\left(\mathrm{CO}_{2}\right)$ and other green house gases (methane, nitrous oxide, and fluorinated gases) that contribute to global warming, a major contributor to climate change today. $\mathrm{CO}_{2}$ is the primary greenhouse gas emitted through human activities. The majority of GHGs emanate from burning fossil fuels, mainly from motor vehicles and industry (International Energy Agency 2012). These emissions have risen steeply over the last century with some cities now being covered in smog that not only reduces visibility, but also reduces air quality, generating air pollution which in turn can cause major respiratory issues and associated health complications. Smog generally can affect plant development and human health, as well as cause damage to materials such as rubber, textiles, and paint (Marcella et al. 1957; Rani et al. 2011). Three major outdoor air pollution problems are industrial smog from burning coal, photochemical smog from motor vehicle and industrial emissions, and acid deposition from coal burning and motor vehicle exhaust (Rani et al. 2011). A wide range of experts have advocated decreasing individual carbon footprints and investing billions to reduce the risks of a major change in the earth's environment (Stern 2008). Green environments can help absorb the $\mathrm{CO}_{2}$ in the air which can be converted into stored carbon through the process of photosynthesis. Different plant species vary in the amount of $\mathrm{CO}_{2}$ they can absorb and this variation is determined by various morphological and physiological characteristics of the plants as well as land use (Houghton 1989). Some characteristics that can help determine which plants would have high carbon assimilation rates include growth rate, leaf area, wood density, and seasonal vegetation changes, including whether they are deciduous or not.

\subsubsection{Disaster Prevention and Reduction}

Disaster prevention and reduction is a key contribution of green areas in urban environments when carefully planned. Experience from Japan has shown that areas with trees along elevated highways and railways have proved very important as a disaster prevention and reduction method because the trees form important barriers to fires and offer support from total collapse due to earthquakes or tsunamis (Miyawaki 1998). In Kenya, congestion of highways in urban areas such as Nairobi is forcing planners to consider elevated highways as a way of increasing capacity to handle vehicle traffic efficiently. Therefore, an integrated transport management strategy should incorporate planting the right species that can mitigate such incidents if they were ever to occur.

Headlight glare from opposing traffic can cause potential safety problems and plants can serve to reduce the glare during night time driving. The most favored design of highways today is to have dual carriageways that can handle several lanes of traffic going each way. Even when the carriageways are separated by ample 
distance between them you will find that headlamp glare from motor vehicles will always affect other motorists around corners or bends. Glare can be reduced by the use of wide medians, separate alignments, earth mounds, plants, concrete barriers, and glare screens (WSDOT Design Manual 2013). Long-term maintenance should be considered when selecting the treatment for glare but some solutions can be expensive (e.g., glare screens). Plants can be used to create natural light barriers between the highways and consequently block light from headlamps, making night time driving safer and more pleasant. However, such greening programs need to be based on informed decisions regarding what species to plant where, and at what distances from the roads and road junctions. For example, if wrongly planted or mixed, trees can block the driver's view at junctions and clear zones, thereby increasing risk of accidents, or of impact if the driver loses control of the motor vehicle. It is essential to understand the branching system and/or strength to ensure selected species do not break off easily, which is important in withstanding high winds, and consequently enhancing the safety of pedestrians, motorists, and utility lines. Some tree species, e.g., many species of Eucalyptus will snap during the rainy season when they cannot support the large volume of water they take up during this time combined with the effects of higher wind speeds or wind gushes.

The other importance of having vegetation in between dual carriageways or along highways is that it can act as a barrier when accidents occur. While tree removal may be beneficial to reduce the impacts of driving errors (e.g., angle crashes), appropriate vegetation may help to reduce speed and magnitude of impact in case of an accident. This can be achieved through frangible planting-planting which breaks under the impact of a motor vehicle (and hence helps to stop the vehicle). Generally trees and shrubs with a mature trunk diameter of less than $100 \mathrm{~mm}$ at around $500 \mathrm{~mm}$ above ground level are considered frangible. Vegetation can act as softer barriers than concrete or metal and therefore reduce impacts during an accident and increase the chance that injuries or loss of life are minimized.

\subsubsection{Beautification}

Since time immemorial, man has used different types of plants for beautification ranging from herbs and shrubs to trees. Plants of different species produce a wide variety of flowers with pleasant odors and colors. Flowers, being the evolutionary adaptation to help plants in pollination therefore have different shapes, colors, scents, and rewards such as pollen or nectar to attract specialized animal pollinators. Man has proceeded to breed and domesticate other flowers whose only purpose is beauty, usually deriving from the flower and/or leaf color. These plants are used both indoors and outdoors, and grown in a variety of ways including in pots, on walls and rooftops, in lawns and hedges, and in home gardens, as well as in parks and urban forests. Local vegetation that is well understood (e.g., in terms of flowering pattern and cycle, scents and vegetative growth) can be selected and incorporated in urban greening programs and serve the additional benefit of beautification. 


\subsubsection{Nutrition (Fruits)}

Urban vegetation planning can include local and exotic fruit species. This can be in home gardens, public parks, and within compounds of institutions and office complexes. In Sweden for example, it is not uncommon to find fruit trees such as apples in public parks and people are free to pluck and consume as they relax or pass through these areas. In Kenya, fruits such as mangoes, avocadoes, plums, and coconuts can be incorporated in urban greening programs. At present, it is popular to grow fruit trees in urban home gardens but not common in public places.

\subsection{Case Study: Opportunities in Urban Environments}

\subsubsection{Restoration of an Urban Green Environment Using Potential Natural Vegetation at the University of Nairobi, Kenya}

The College of Biological and Physical Sciences of the University of Nairobi sits between Kirichwa Kubwa and Kangemi Rivers, and can be described as the zone where altitudinal cline starts accompanied by obvious remnants of upland dry forest vegetation to the west, south west, and north west, and separates the savannah landscape to the east and south east. This includes the riverine tree species such as Syzygium and Albizia. It is a unique and picturesque location that Ewart Scott Grogan (18741967), one of the pioneer colonial settlers, chose to build a home. Remnants of original vegetation show that the upland dry forest was continuous and spread from Karura upwards towards Ngong forests. However, only a few of the original species remain since the colonial settlers planted exotic species such as Eucalyptus (to drain the wetlands next to the two rivers), pine, and other species such as Jacaranda for beautification purposes. In addition, substantial infrastructure developments have taken place with the former residence converted into a campus of the University of Nairobi. The college is one of the few remaining areas of Nairobi with a natural feel and enjoys a clean and fresh environment compared to the city center barely $2 \mathrm{~km}$ away.

It therefore offers an opportunity not only to preserve the environment but also to restore it with original natural vegetation that has evolved in place for millions of years, while still offering a pristine educational environment for present and future generations.

To restore an environment with potential natural vegetation, one needs to understand the kind of vegetation that existed before human disturbance. Since 2007, our team led by Professor Kazue Fujiwara has conducted some intensive studies in Karura and Ngong forests with the aim of understanding vegetation composition and the social relationships among species. From these studies, we were able to identify common species that form all levels of vegetation in a forest from the canopy (T1) and understory (T2) canopies down to shrub and herb layers, and use 
this mix to create a natural forest by planting seedlings using the Miyawaki method (Miyawaki 1998). The selected species were Shrebera alata, Rawsonia lucida, Cassipourea malosana, Vepris simplicifolia, Drypetes gerrardii, Elaeodendron buchananii, Croton megalocarpus, Brachylaena huillensis, Calodendrum capense, Ficus thonningii, Warburgia ugandensis, Olea europaea ssp. Africana, Olea capensis ssp. Hochestetteri, Ehretia cymosa, Markhamea lutea and Cordia africana. The evenness of the above species was matched to ratios close to their natural distributions as we had found them in the natural forest studies such that, for example, there were more $W$. ugandensis, C. capense, C. megalocarpus, B. huillensis, and C. africana in the mix than S. alata, E. cymosa, F. thonningii, and R. lucida.

In designing an urban forest, understanding the species to plant is critical but also other important considerations come into play. Urban areas have zones such as recreational areas, roads, buildings, rivers, etc., each with their own characteristics, and therefore specific considerations and informed decisions should be applied in each case. For example, planning of tree planting in recreational areas such as parks needs to take into consideration spatial arrangements to enhance movements of people, as well as placement of benches. Therefore the pattern and intensity of planting must be well planned. In addition, the species selected should not break off easily or be uprooted by strong winds because of the potential dangers of them falling on people. In the case of Chiromo campus, we considered that the area chosen was also used for recreational purposes and so we could not plant a continuous forest. We decided to take advantage of the less utilized part of the area which formed step-like contours along the gradient of the slope (Fig. 18.6). Trees also do better on a slope than on a flat area, mainly because slopes have better drainage.

The site was prepared by clearing grass and bushes, and then holes of at least $0.3 \mathrm{~m}$ wide by $0.6 \mathrm{~m}$ deep were dug at a density of $3 \mathrm{holes} / \mathrm{m}^{2}$. Seedlings were sourced from the local community groups as well as the Kenya Forestry Services nurseries. The 16 species were then mixed randomly and placed in each hole, with over 2,000 seedlings planted. The planting was undertaken by the university community, including members of staff and students, along with Japanese researchers and volunteers (Professor Miyawaki and Professor Fujiwara, as well as other scientists and volunteers). The student participation was very important because they were able to learn firsthand, as well as being able to take the experience out of the University when they finished their degrees. On conclusion of the planting, mulching from cut grass was placed around each seedling to prevent water loss and soil erosion. Management (weeding and replacement of any dead seedlings) has been ongoing since then and is expected to continue for a total of 3 years, at which point the seedlings are expected to be big enough.

\subsubsection{Seedling Performance}

The height of the seedlings was measured in September 2013 after 16 months of growth and the performance had been very good (Fig. 18.7). Some of the species had grown very fast with $S$. alata attaining the best mean growth of $211 \mathrm{~cm}$ (followed 


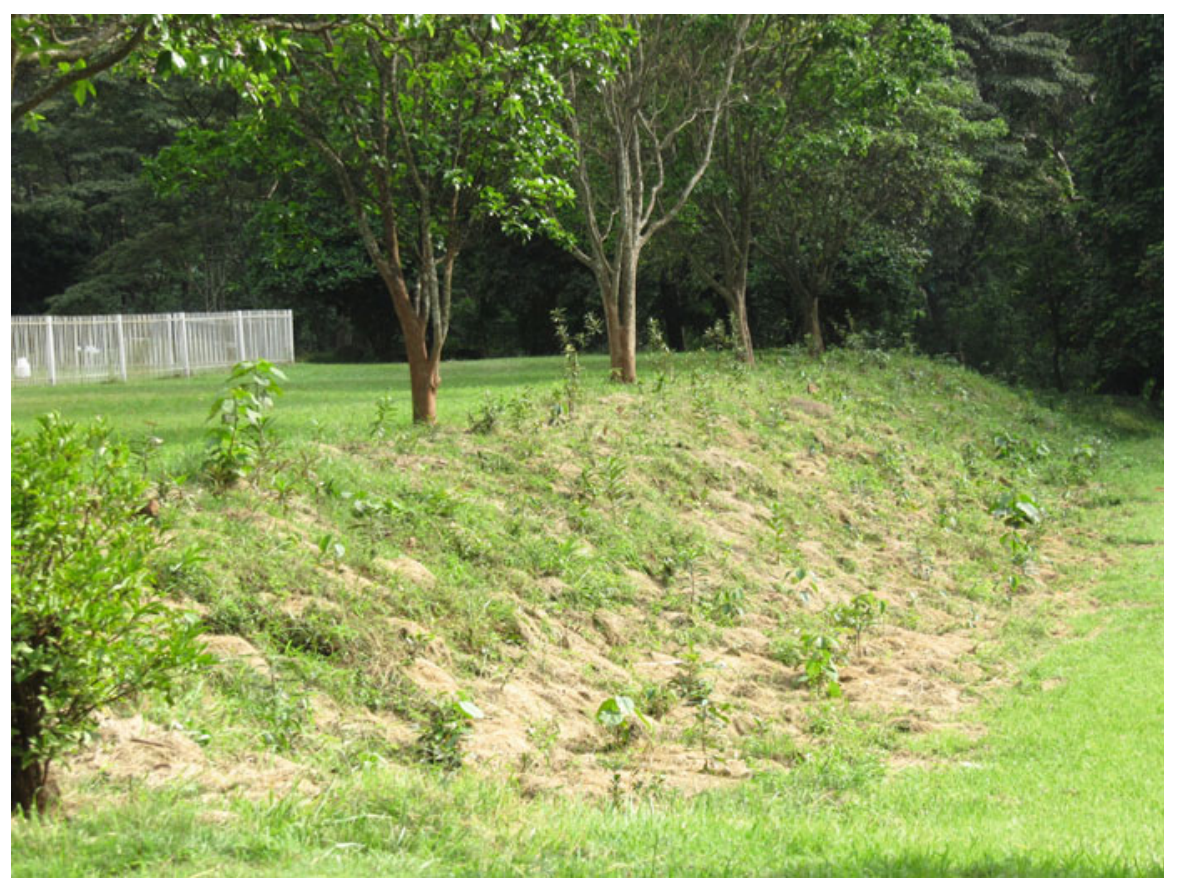

Fig. 18.6 Newly planted site at the University of Nairobi with seedlings about $43 \mathrm{~cm}$ in height after 2 months (Photo dated: 28.06.2012)

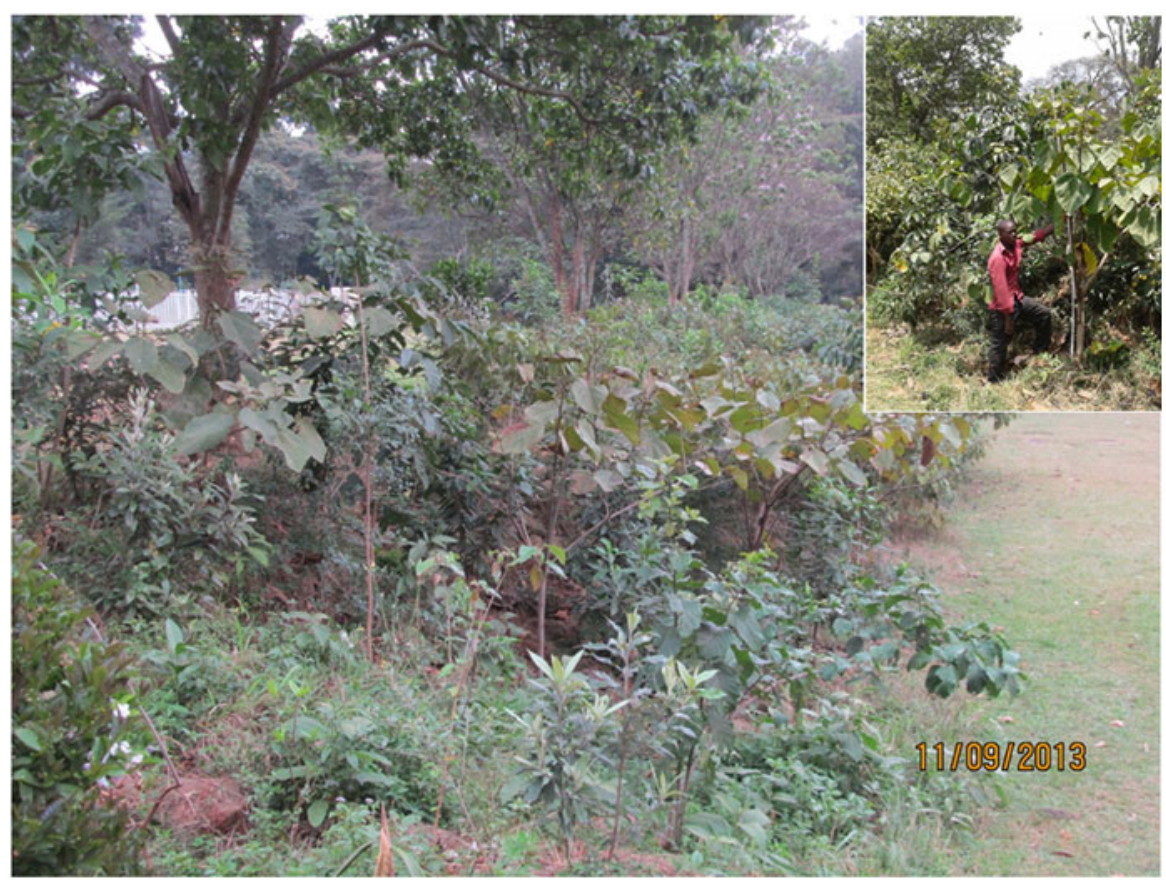

Fig. 18.7 Same site after 16 months with some seedlings exceeding $2 \mathrm{~m}$ in height (Inset: Measuring height of Cordia africana-almost twice as tall as the person holding the measuring ruler) 


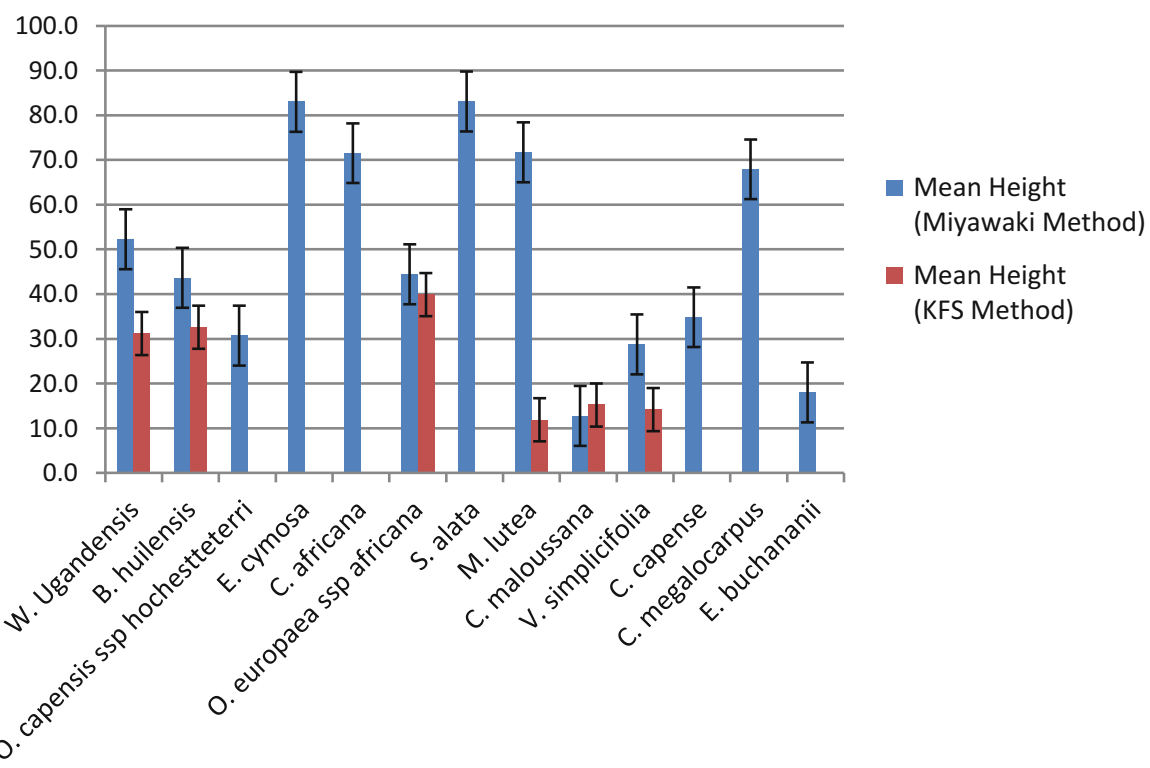

Fig. 18.8 Height of the different species after 16 months. Red bars compare some of the same species planted at the same time at a low density using the regular method

closely by E. cymosa $(210 \mathrm{~cm})$, M. lutea $(182 \mathrm{~cm})$ and C. Africana $(181 \mathrm{~cm}))$ (Fig. 18.8). The slowest mean growth was that of $C$. malousana $(32.5 \mathrm{~cm})$ and E. buchananii $(45.7 \mathrm{~cm})$. The rest of the species had median growths varying between 71 and $132 \mathrm{~cm}$. Compared to the traditional planting method with a spacing of $1 \mathrm{~m}^{2}$ between the seedlings, the Miyawaki method showed better performance in the few species that could be compared (Fig. 18.8).

\subsection{Conclusion}

Scientifically informed decisions can help restore urban green vegetation by helping in identification of the right species and their combinations. The method of rehabilitation is also important as it is evident here that the Miyawaki method favors faster establishment of vegetation and therefore it is possible to regenerate a quasi natural forest over much shorter temporal scales. Involving communities, the public, or students is important in long term success since they learn and take the experiences to different parts of a country as well as taking ownership and practicing sustainable environmental practices on their own initiative.

Open Access This chapter is distributed under the terms of the Creative Commons Attribution Noncommercial License, which permits any noncommercial use, distribution, and reproduction in any medium, provided the original author(s) and source are credited 


\section{References}

Bolund P, Hunhammar S (1999) Ecosystem services in urban areas. Ecol Econ 29:293-301

Chang J, Collins G (2008) Landscape guideline. Landscape design and maintenance guidelines to improve the quality, safety and cost effectiveness of road corridor planting and seeding. RTA, Sydney

Houghton RA (1989) The long-term flux of carbon to the atmosphere from changes in land use. Extended abstract from the third international conference on analysis and evaluation of atmospheric $\mathrm{CO}_{2}$ data present and past. Hinterzarten, 16-20 October 1989. Environmental Pollution, Monitoring and Research Programme 59. World Meteorological Organization

International Energy Agency (2012) $\mathrm{CO}_{2}$ Emissions from fuel combustion highlights. IEA Publications, Paris

Lemieuxa PM, Lutesb CC, Santoiann DA (2004) Emissions of organic air toxics from open burning: a comprehensive review. Prog Energ Combust 30:1-32

Marcella J, Noble W, Went FW (1957) The standardization of Poa Annua as an indicator of smog concentrations. I. Effects of temperature, photoperiod, and light intensity during growth of the test-plants. Plant Physiol 32:576-586

Miyawaki A (1998) Restoration of urban green environments based on the theories of vegetation ecology. Ecol Eng 11:157-165

Muller N, Fujiwara K (1998) Biotope mapping and Nature conservation in cities Part 2: Results of a pilot study in the urban agglomeration of Tokyo (Yokohama City). Bull Inst Environ Sci Technol Yokohama Natn Univ 24:97-119

Rani B, Singh U, Chuhan AK, Sharma D, Maheshwari R (2011) Photochemical smog pollution and its mitigation measures. J Adv Sci Res 2:28-33

Stern N (2008) The economics of climate change. Am Econ Rev 98(2):1-37

Straskraba M (1993) Ecotechnology as a new means for environmental management. Ecol Eng 2:311-331

The Economics of Ecosystems and Biodiversity (TEEB) (2011) TEEB manual for cities: ecosystem services in urban management. www.teebweb.org

The Economist Intelligence Unit (2013) A summary of the liveability ranking and overview. The Economist Group, London, UK

WSDOT Design Manual (2013) Roadside safety. 1600-01-1600-22 